\title{
SALONES Y MARCHANTES DE ARTE EN LA ARGENTINA (1890-1925)
}

\author{
POR \\ RODRIGO GUTIÉRREZ VIÑUALES \\ Universidad de Granada
}

\begin{abstract}
The present work points his attention in the exhibition's rooms in Argentina at the end of the 19th. century and the beginnings of the 20th, its caracteristics and main activities, and the art marchands labor during the same period. It is a contribution about some aspects of the argentinian art market, that pretends to bring new facts and contributes to think about an open debate on a research topic to be deepen.
\end{abstract}

\section{Acerca de los primeros salones privados en la Argentina}

En comparación con los adelantos producidos en el llamado «ámbito artístico» europeo, a lo largo del siglo XIX, el caso de la Argentina, como el de otros países iberoamericanos, experimentó una irregularidad considerable, marcada por evoluciones lentas y progresos no fácilmente advertibles. En el país rioplatense la primera academia que desarrolló actividades con cierta solidez y continuidad fue la Sociedad Estímulo de Bellas Artes surgida en 1876. Fue en el seno de esta institución donde se generaron, en los años noventa, las exposiciones de El Ateneo - antecedente de lo que sería el Salón Nacional a partir de 1911 - y la creación del Museo Nacional de Bellas Artes (1895).

Para ese entonces, y gracias a distintos emprendimientos privados, ya se organizaban en Buenos Aires numerosas exposiciones de arte; el número de éstas como también el de los salones, se vería aumentado en los primeros años del siglo XX. Esta situación fue justamente el resultado de una tardía herencia de Europa, en donde hacía ya tiempo que el vuelco se había producido. «La creación de los salones..., donde a partir de la segunda mitad del XVIII, periódicamente se exponían a la contemplación del público las obras de arte, fue un claro antecedente de las galerías comerciales actuales y supuso para el artista tener que enfrentarse con una hasta entonces insólita situación de consumo anónimo, esos clientes sin rostro del mercado, la libertad conquistada frente al encargo a priori... propició el pintoresquismo, a veces trágico de la bohemia...» ${ }^{1}$.

Con los salones y el ánimo de apertura de artistas y comitentes aparecieron las exposiciones de arte, primero las colectivas y más adelante «se inauguró la era de las exposiciones particulares, que se fueron haciendo cada vez más frecuentes en el curso del siglo XIX... En verdad, el interés del artista por exponer aisladamente conjuntos de su producción y el deseo del público de conocer tales obras, impulsaron la creación, al margen de las organiza-

1 Francisco Calvo Serraller, «La pintura de las Luces», El País, Madrid, 31 de julio de 1984, Suplemento «Diderot y la Ilustración», p. VIII. 
ciones oficiales, de las galerías de exposición particulares y de la nueva industria del marchand...» ${ }^{2}$.

«En resumen —afirmó Payró-, gracias a la Revolución Francesa, aparecieron tres formas nuevas de comunicación del artista con el gran público: el Museo, propiedad colectiva, el Salón oficial, abierto periódicamente a vastas multitudes y la exposición particular. La intensificación del contacto del artista con las masas tuvo trascendencia... ${ }^{3}$.

En la Argentina, al buscarse los antecedentes del Salón Nacional, además de las señaladas exposiciones de El Ateneo, se han tomado como referencias casi ineludibles las llevadas a cabo en la primera década de nuestro siglo por la Sociedad de Aficionados y el grupo «Nexus». Debe remarcarse el hecho de que los salones donde se llevaron a cabo todas esas exhibiciones fueron salas privadas, como Witcomb, Costa, Ruggero \& Bossi, etc., y no en sedes oficiales, puesto que la oficialidad, esto es el Estado, tardó cerca de veinte años en convertirse en partícipe de las actividades artísticas en el país, terminando con dicha situación en 1895 al nacionalizarse el Museo de Bellas Artes. Witcomb, el más destacado estudio fotográfico de la época en la Argentina, y Costa hicieron un «esfuerzo» por convertirse en salas exclusivas de arte, lo que demuestra los lazos existentes entre académicos y empresarios privados.

Las características físicas de los salones fueron de lo más variadas. En el caso del Salón Costa, y para llegar al amplio salón donde en 1905 y 1906 expuso quien en los años veinte sería el máximo exponente de la pintura de paisaje en el país, Fernando Fader, debía trasponerse primero la parte central del negocio, atiborrada de porcelanas, marfiles, bronces y caireles de la época. Los cuadros aparecían colgados unos encima de otros y la falta de espacio llevaba a que la posibilidad de una correcta colocación quedase supeditada al deseo de exponer la mayor cantidad de obras posibles ${ }^{4}$ (fig. 1 ).

En España la situación se planteaba en términos similares. Bernal Muñoz describió la sala de Carlos de Haes en la Exposición de Bellas Artes de 1899 como «una larga sala cuyo eje aparece ocupado por grandes divanes de terciopelo y en cuyo centro aparece el busto del pintor, presenta sus muros totalmente tapizados de cuadros de diferentes tamaños, puestos sus marcos en contacto, sin orden ni concierto, en forma abigarrada...» ${ }^{5}$.

Podemos hacer referencia a lo que ocurría en este sentido en la ciudad de Mendoza, a la que a principios de siglo arribaron artistas-mercaderes con obras europeas junto a algunas argentinas para exhibirlas en algún salón comercial, en el hotel donde se hospedaban o en algún club. Aquéllas que no se habían vendido se terminaban subastando el último día.

Fue éste el caso del pintor español Pedro Blanqué, quien habiendo llegado por primera vez a la capital cuyana entre 1885 y 1886, regresó en 1903 trayendo cuadros de historia, costumbres y paisajes suyos, más una colección de cerca de doscientas obras entre autores locales y europeos. Más adelante, en 1908, presentó sus obras Desiré Bourrely. En 1912, con el profesor italiano De Conciliis, arribaron obras de Favretto, Segantini, Morbelli y hasta una

2 Julio E. Payró, Pintura moderna, 1800-1940. Buenos Aires, Editorial Poseidón, p. 19.

3 Ibídem., p. 20.

${ }^{4}$ Sobre la escenificación de las exposiciones desde el siglo XVIII y hasta nuestros días, puede consultarse el trabajo de Luis Alonso Fernández, «Presentación, relato y representación escénica de la exposición», Revista de Museología, Madrid, octubre de 1997, núm. 12, pp. 79-87.

5 José Luis Bernal Muñoz, «Museos y exposiciones en el cambio del siglo, 1897-1903», Cuadernos de Arte e Iconografía, Madrid, Fundación Universitaria Española, t. III, núm. 5, 1er. semestre de 1990, p. 88. 
de Canaletto, «La tumba de Petrarca», que fue rifada a beneficio de una institución de caridad. Dos años después presentó su producción el barón Eschaseriaux du Ramet ${ }^{6}$.

En el Uruguay, país culturalmente vinculado a la Argentina hasta tal punto que, con justa razón, se habla de un «arte rioplatense», la situación se presentó aún bastante peor, inclusive organizando los artistas sus muestras en los propios talleres. Gabriel Peluffo Linari cita un testimonio acerca de la sede en la que expusieron en 1930, a su regreso a Montevideo provenientes del extranjero, el pintor paisajista José Cúneo y el escultor Bernabé Michelena, en donde se habla del «inmundo antro que es el sótano del Ateneo -pulgas, humedad, ratas, oscuridad, aire viciado-...» ${ }^{7}$.

En la segunda década del siglo, en Buenos Aires, ya la situación había cambiado y las salas de exposición, y por tanto las posibilidades de presentar obras para los artistas - esto sin contar al Salón Anual inaugurado en 1911-, habíanse multiplicado. Un texto de la época destacó que durante el invierno «las exposiciones, principalmente de pintura, abundan, y los más afamados artistas sólo pueden disponer de diez o quince días para darnos a conocer los frutos de su ingenio» ${ }^{8}$.

Para ese entonces surgían en Buenos Aires galerías como la de Philipon, sucursal de la parisina del mismo nombre, que albergó en 1912, año de su inauguración, una muestra del sevillano Gustavo Bacarisas, y la Galería de Londres dedicada a difundir la pintura inglesa. Philipon, organizada por Ignacio Caride y Pedro Bercetche, habría desaparecido hacia 1914; la segunda, regenteada por Eduardo Haynes, tampoco llegó a alcanzar renombre, lo mismo que las denominadas L'Eclectique, abierta en 1912 por el pintor francés Pierre Calmettes que antes había estado ligado al Salón Fumières, y Casa Brunner sucursal de la parisina del mismo nombre ${ }^{9}$.

Hallábase en las vecindades de Fumières, existente en los días del Centenario, la Cooperativa Artística, establecimiento comercial dedicado a la venta de útiles artísticos y habilitado como sala de exposiciones en la que albergó muestras como la de los trabajos rechazados en el Salón Nacional de 1914 -también llamada Primer Salón de Recusados-o varias de las realizadas por Stephen Koek-Koek. Los nombres de Walter de Navazio y Víctor Torrini están también ligados a la Cooperativa; el primero como habitué de las tertulias que allí se hacían, y Torrini por su labor de marchand y mecenas vinculado directamente a la tienda (fig. 2).

Tras el surgimiento en la misma sede de «Boliche de Arte», en 1927, la Cooperativa habría desaparecido. El nuevo comercio se inclinó por apoyar las manifestaciones artísticas de avanzada, encontrándose así las nuevas tendencias con sala propia en Buenos Aires. En ese año funcionó también el Salón Florida, dirigido por el escritor Raúl Scalabrini Ortiz, que vino a agregarse a otros instalados en 1926: la agrupación de gente de letras y artes autodenominada con el muy madrileño nombre de «La Peña», cuya sede fue el Café Tortoni; la librería El Bibliófilo, que organizó exposiciones a través de los señores Viau y Zona; y,

6 Marta G. de Rodríguez Brito, «Extranjeros en el campo de las artes plásticas a principios de siglo en la Provincia de Mendoza», Cuadernos de Historia del Arte, Mendoza, Universidad Nacional de Cuyo, 1986-1987, vol. 12, pp. 103-105.

${ }^{7}$ Cartel, Montevideo, agosto de 1930, Núm. 8. Cit.: Gabriel Peluffo Linari, Historia de la pintura uruguaya, Montevideo, Ediciones de la Banda Oriental, 1986-1988, fasc. IV, p. 74.

8 R. Monner Sanz, «Léonie Matthis», La Ilustración Artística, Barcelona, t. XXXII, núm. 1.656, 22 de septiembre de 1913 , p. 620.

9 Francisco Palomar, Primeros salones de arte en Buenos Aires, Buenos Aires, Municipalidad de la Ciudad, 1962, pp. 142-143 y 150. 
finalmente, la Nordiska Kompaniet, cuya existencia como sala de muestras llegó a prolongarse por cinco lustros ${ }^{10}$.

Debemos señalar también el surgimiento de otros salones como el de Chandler y Thomas, al 200 de la calle Florida, que hacia 1930 pasó a denominarse «Chandler y Zuretti» y finalmente «Zuretti» a solas. En 1924 surgió la Galería Van Riel, emprendimiento del dibujante y pintor italiano Franz Van Riel dedicado desde hacía un tiempo a la fotografía. Este marchand había trabajado como ilustrador en el diario La Prensa de Buenos Aires donde habría trabado amistad con el crítico de arte del periódico, Manuel Rojas Silveyra, decidiendo ambos editar y conllevar la dirección, desde 1918, de la distinguida revista de arte Augusta. Las salas de Van Riel pasaron a ser ocupadas en 1927 por los Amigos del Arte hasta su extinción en 1943, año en que el marchand reabrió su galería ${ }^{11}$.

A finales de los años veinte los progresos se manifestaban con evidencia y la situación de crecimiento se hallaba consolidada por completo. «Amigos del Arte, están desarrollando un programa extraordinario de intensa actividad. Tal es la demanda de sus salas, que las muestras se abrevian para dar lugar a los innumerables pedidos. Así vemos, que actualmente ocupan su local obras de seis artistas y, si agregamos que otros se encuentran representados en Witcomb, Müller, Camuatí y La Peña, únicamente, podemos advertir que, en el momento, doce pintores exponen esta semana en Buenos Aires, donde también se realizan varias exhibiciones de conjunto; a lo que debemos agregar, el Salón de Santa Fe, inaugurado el sábado, y, el Nacional, que en estos instantes se prepara. Resulta pues -n este año malo-más desproporcionado que nunca a nuestro ambiente tal cantidad de exposiciones, por la imposibilidad de que un público preparado, en relación, las apoyen en la medida de que ellas no resulten un verdadero sacrificio, pues esa desproporción desequilibra hasta los presupuestos oficiales, cuyo monto, en tal rubro, no permite extralimitaciones» ${ }^{12}$.

Los marchantes y las ventas de obras de arte.

«Cuanto más totalmente te vuelves marchand, más te vuelves artista». (VAN GOGH, Vincent. Cartas $a$ Theo. Trad. Víctor A. Goldstein. Buenos Aires, Editorial y Librería Goncourt, 1980, p. 302).

Tras hablar del surgimiento y la proliferación de las galerías de arte en la Argentina durante las primeras décadas de siglo, señalaremos algunas noticias respecto de la labor de los marchantes de arte, en su doble función de organizadores de exposiciones y de mantenedores, económicamente, de la labor de los artistas.

El destino ha querido que entre los pocos testimonios escritos que han quedado como fuentes para abordar el tema, se conserve una buena parte de la correspondencia entre quienes fueron el marchand y el pintor más importantes del período, Federico Carlos Müller y Fernando Fader respectivamente, y que sin duda alcanzaron ese merecido rango el uno gracias a el otro y viceversa.

\footnotetext{
$10 \quad$ Ibidem., pp. $135-140$ y $148-150$.

11 Ibídem., pp. 143-145.

12 «En las salas de Amigos del Arte», La Razón, Buenos Aires, 4 de septiembre de 1929.
} 
Müller comenzó ejerciendo una suerte de mecenazgo con respecto a un Fader derrumbado económicamente tras el fracaso de sus empresas hidroeléctricas en Mendoza ${ }^{13}$. Otros casos aislados de manutención fueron los de Víctor Torrini con el propio Fader y con otros artistas argentinos, el del doctor Alejandro Carbó, de Córdoba, apoyando al pintor José Malanca al decidir éste estudiar en Italia, o el más lejano aun en el tiempo de Juan Manuel Blanes que fue ayudado por el general Justo José de Urquiza. Emilio Pettoruti tuvo como mecenas en Milán al que fue considerado «mejor crítico de arte» de la ciudad, Raffaello Giolli, quien le contrató para ilustrar libros infantiles y le puso en contacto con los artistas milaneses.

Otro sistema que funcionó a la perfección fue el de la ejecución de obras por encargo, situación repetida especialmente al tratarse de pinturas representando temas históricos —en la Argentina podemos citar casos como los de José Moreno Carbonero, Pedro Subercaseaux o Antonio Alice- ${ }^{14} \mathrm{y}$ en monumentos públicos y funerarios. El retrato también recuperó el prestigio perdido en la segunda mitad del siglo XIX como consecuencia de su momentánea absorción por la fotografía, cuya novedad sedujo a la clientela haciendo a un lado, en cierta manera, la exclusividad del retrato pictórico.

En el XX, pues, volvió a ser éste una señal de reputación, tanto para el retratado como para el artista, quien además de sus beneficios por vender la obra, supo ganar consideración en el ambiente por haber retratado a tal o cual personalidad. Esto quedó demostrado en la importante presencia de retratos en los primeros veinte salones nacionales (1911-1930), donde sólo fueron superados en número por los paisajes.

Cesáreo Bernaldo de Quirós, consolidado durante los años veinte como el pintor costumbrista más destacado de la Argentina ${ }^{15}$ y que se instaló en norteamérica entre 1932 y 1936, más allá de los problemas económicos que sufrió Estados Unidos a partir del «crack» de la bolsa neoyorquina de 1929, pudo incrementar sus cuentas realizando retratos de aristócratas de ese país y diplomáticos argentinos temporalmente radicados allí, como el caso del embajador Felipe Espil. Seguía así, en cierta medida, un trayectoria similar a la vivida por el vasco Ignacio Zuloaga en París durante la primera mitad de la segunda década de siglo donde realizó numerosísimos retratos, especialmente de millonarios sudamericanos y damas de buena posición (fig. 3).

Volviendo la mirada sobre la figura de los marchantes en la Argentina, en esta rama ninguno alcanzó la excelencia del alemán Federico C. Müller. Su accionar, sin precedentes en nuestro ambiente artístico fue decisivo en la imposición de la pintura de Fader como «primer pintor nacional». Su dedicación motivó que éste tuviera los medios económicos para poder producir sus obras que de otra manera hubiese sido posiblemente muy difícil, salvando las etapas en que Müller tuvo problemas monetarios, en especial en el período de post-guerra, dado que tenía negocios en Alemania, sumida a la sazón en una profunda crisis. De ahí la ruptura temporal con Fader quien se había acostumbrado a vivir sin sobresaltos.

13 Habiendo fallecido en 1905 su padre Carlos, importante empresario en la provincia de Mendoza, Fader le reemplazó en la dirección de obras hidroeléctricas, dedicándose a ellas a partir de 1908 casi con exclusividad. La quiebra empresarial producida en 1914, a la par de dejarle desposeído de bienes, significó su retorno a la pintura, consagrándose como el artista más reconocido de la Argentina durante los años veinte.

14 Véase nuestro trabajo «La pintura de historia en la Argentina», Atrio, Sevilla, 1996, núms. 8-9, pp. 197-214.

15 Fue autor de la serie «Los Gauchos, 1850-1870» que tras ser presentada en Buenos Aires en 1928 se exhibió el año siguiente en el Círculo de Bellas Artes de Madrid —exposición visitada por el rey Alfonso XIIIy en el Real Círculo Ecuestre de Barcelona, antes de pasar a otras capitales europeas y norteamericanas. 

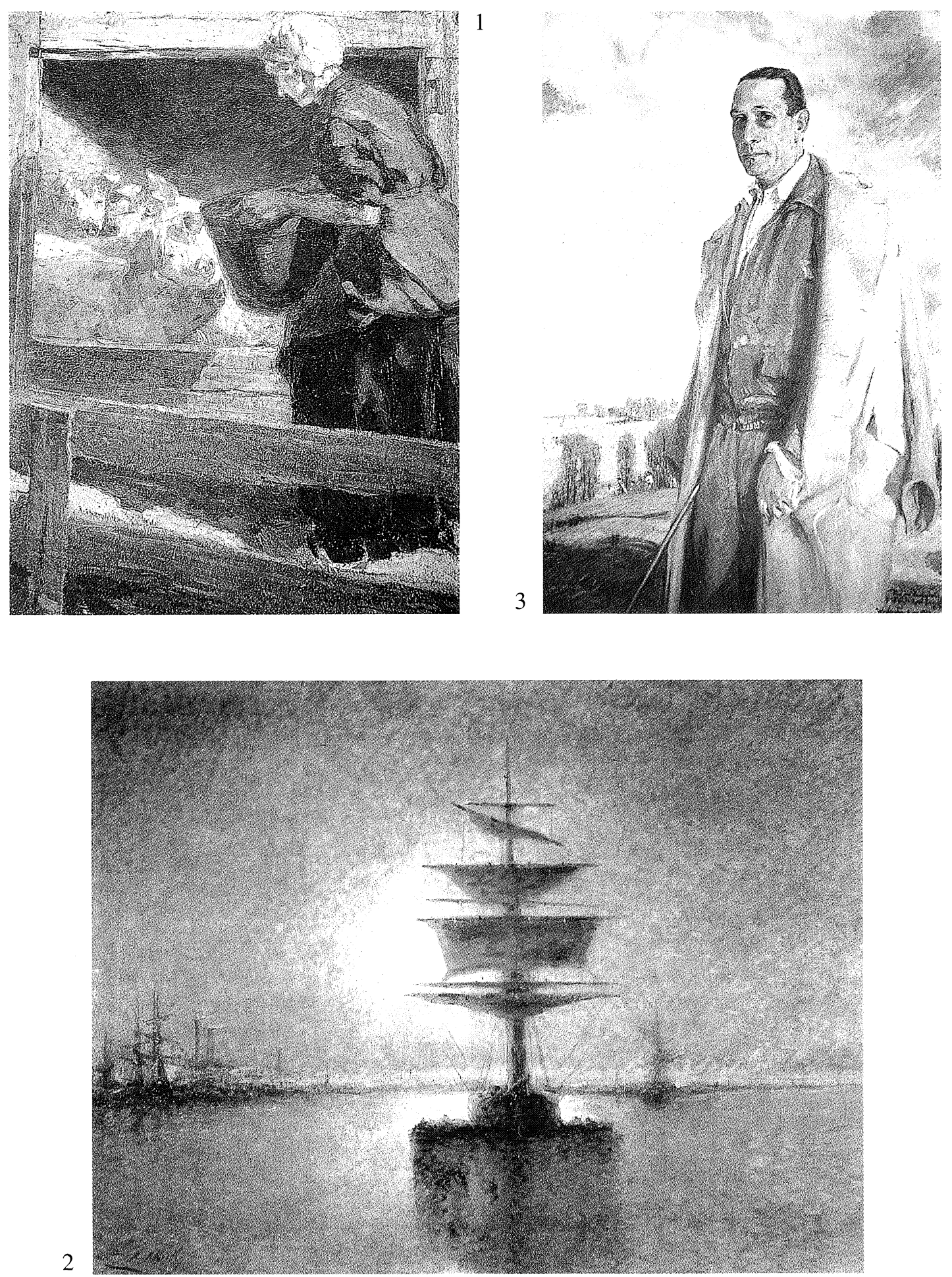

Figura 1. Fernando Fader, «La comida de los cerdos», 1904. Buenos Aires. Museo Nacional de Bellas Artes (de la exposición Fader, Salón Costa, Buenos Aires, 1905).

Figura 2. Stephen Koek-Koek, "Amanecer», 1919. Buenos Aires. Col. Zurbarán Galería (de la exposición Koek-Koek, Cooperativa artística, Buenos Aires, 1919).

Figura 3. Cesáreo Bernaldo de Quirós, «Retrato del Embajador Felipe Espil», 1933. Buenos Aires. Col. privada. 
Müller llegó a Buenos Aires en 1905. Primeramente se asoció con un anticuario, independizándose en 1909 al instalarse por cuenta propia en un local de Florida al trescientos, al que llamó «Renacimiento». Se dedicó a la importación y venta de objetos de arte, sobre todo porcelanas de famosas manufacturas centroeuropeas. Hizo algunas muestras de pintura en los sótanos del local. Participó en la organización de la sección alemana en la Exposición Internacional del Centenario de 1910, en la que mostró su habilidad de comerciante al adquirir, tras el anuncio de la muerte de Ignacio Zuloaga, «La vuelta de la vendimia», cuadro que devolvió al confirmarse el error de la noticia ${ }^{16}$.

En 1912 y 1913 organizó dos muestras de pintura germana en el Club Alemán de la calle Córdoba de Buenos Aires. El éxito que obtuvo le animó a instalar una galería dedicada exclusivamente al arte en el año 1914, ahora en Florida $935^{17}$. Esta fue inaugurada con una muestra colectiva de artistas argentinos entre los que se contaban Fader, Quirós, Ripamonte y Bermúdez, «con sala, catálogos e invitaciones gratis», y en la que se vendieron «sólo dos cuadros y el señor Müller percibió 110 pesos, el diez por ciento de la venta» ${ }^{18}$.

Tras su descalabro económico de 1914, Fernando Fader se vio amparado por Müller. El pintor reconoció años más tarde, cuando su consagración era una realidad, haber podido abrirse camino con la ayuda del marchand quien le sostuvo durante más de un año, adelantándole una mensualidad que le permitió atender su delicada salud y tomando a su cargo la organización de las exposiciones del artista y la venta de sus telas. Antes Torrini y Pedro Garmendia habían sido intermediarios en la venta de sus obras; Garmendia, inclusive, en 1920, encontrándose en una posición económica complicada, decidió vender por su cuenta catorce telas de Fader que tenía depositadas. Además aportó las obras que conformaron la primera retrospectiva de Fader, en las recientemente inauguradas salas de la Asociación Amigos del Arte en 1924, época en las que el paisajista se encontraba distanciado de Müller (fig. 4).

En sus cartas de 1916 y 1917 a Müller, Fader manifestó haber estado proyectando la realización de una exposición en España, lo que después rehuyó ante la casi seguridad de no tener éxito financiero; la guerra europea cerró las puertas a este tipo de concreciones. La idea inicial era hacer la muestra enviando a alguien desde la Argentina con los cuadros o contratando una firma comercial dedicada al arte en España. El artista y su marchand pretendieron reflotar el plan, aunque sin éxito, en 1927.

En 1926, cuando Müller se encontraba presto a abrir una nueva galería en Buenos Aires, tras su crisis iniciada en 1924 con el cierre del salón anterior, Fader le aconsejó: «Releyendo su carta me olvidé de contestarle su pregunta referente a un prólogo para la inauguración de su nuevo local. Creo mejor no. Hacer como si nada hubiera sucedido. Ud. ha cambiado de local, pero no de propósito. Ahora si se puede conseguir que Pagano o los críticos aprovechen la exposición para decir dos palabras de su vuelta tanto mejor. Pero esos catálogos con prólogo casi siempre resultan un poco ingenuos y se prestan más a comentarios maliciosos que a otra cosa. En todo caso asegúrese la presencia de Alvear ya sea en la inaugu-

${ }^{16}$ El 11 de julio de 1910, se produjo la muerte del padre del artista, don Plácido Zuloaga, y por error, al transmitirse la noticia a América, muchos periodistas entendieron que el fallecido era el artista. La confusión generó una fiebre de ventas de obras presentadas por Zuloaga en la Exposición del Centenario, algunas de las cuales - como en el caso de Müller - fueron anuladas tras aclararse el suceso. (Ver: Enrique Lafuente Ferrari, La vida y el arte de Ignacio Zuloaga, Madrid, Revista de Occidente, 1972, p. 106).

17 Antonio Lascano González, Fernando Fader, Buenos Aires, Ediciones Culturales de la Argentina, Ministerio de Educación y Justicia, 1966, pp. 26-27.

18 «Treinta años de arte en Florida», Qué sucedió en 7 días, Buenos Aires, 12 de diciembre de 1946, p. 32. 
ración o después, más por Ud. que por mí y entonces se le puede hablar de su intención de hacer buenas exposiciones, etc...» ${ }^{19}$.

Este texto nos brinda la posibilidad de reflexionar sobre varios aspectos. En primer lugar el carácter de relación que unía a Fader con su marchand, en la cual vemos al artista aconsejando al propio Müller sobre su «metier». Sin duda, repetimos, es una bendición para los historiadores del arte argentino el poder contar con la existencia de esta correspondencia entre el artista y su marchand. Ayudó en gran parte el hecho de que ambos no residiesen en la misma ciudad y se vieran obligados a comunicarse a través de cartas, las cuales han sido conservadas. Esto no es lo habitual ya que los artistas por lo general residían en Buenos Aires y no debían recurrir a la pluma para comunicarse con colegas y afines, pudiendo hacerlo personalmente, por lo que no han quedado muchos testimonios.

En el buen funcionamiento de la relación que unió a los artistas con los compradores, se manifestaron ciertas situaciones que, si bien no pueden considerarse imprescindibles, el acontecer de ellas supo colocar en mejor posición a los pintores. Entre ellas debe señalarse la importancia de contar con un artículo crítico firmado por una pluma de prestigio en algún diario importante. Obviamente la presencia en la exposición del eventual presidente de la Nación se manifestó también como un signo de vital importancia en el éxito de la misma. Figueroa Alcorta y Alvear fueron, en tal sentido, propensos a hacer acto de presencia en los acontecimientos artísticos.

Estos detalles incidieron a menudo en los potenciales compradores y fueron determinantes en las ventas de obras de arte en la Argentina. No todos fueron tiempos de vacas gordas al respecto. En 1906 Cesáreo Bernaldo de Quirós solamente logró vender tres obras de su exposición en el Salón Costa, las que fueron adquiridas por el Gobierno de la Nación a instancias del diputado Federico Pinedo. Se dijo en la ocasión que si no vendía más ello se debía a los altos precios en que había cotizado sus cuadros, aunque no hay que dejar de tener en cuenta que el tamaño de sus mejores obras era, en general, bastante grande y de difícil colocación en un público más acostumbrado al pequeño cuadro de género y de paisaje.

Sin embargo, el momento de los cambios se fue acelerando. En el tiempo que transcurrió entre el desarrollo de Exposición Internacional del Centenario de 1910 y el estallido de la guerra europea de 1914, el ambiente artístico nacional vivió un «frenesí de adquisiciones» de obras de arte, al decir de Chiappori ${ }^{20}$, lo que trajo una reacción asombrada y azorada de los intermediarios europeos quienes, al tener noticias de tal fenómeno, comenzaron a enviar a modo de ensayo lotes de obras para la venta. Inicióse una «corriente migratoria de marchands», multiplicáronse las salas para exposiciones y aumentó notoriamente la cantidad de «vernissages». En un par de años Buenos Aires se convirtió en el principal mercado transoceánico de pinturas, sólo superado por Nueva York.

Así como hubieron comerciantes honestos, pulularon también en el mercado gran cantidad de oportunistas que, aprovechando tan repentino entusiasmo del público, hicieron su negocio vendiendo telas falsas y mediocres copias a las incipientes pinacotecas particulares. $\mathrm{Al}$ conocerse la frecuencia de tales maniobras, además de la divulgación hecha por los publicistas de arte de los mil trucos existentes en Europa para «fabricar» cuadros falsos, el público

19 Archivo Federico C. Müller (en propiedad privada, Buenos Aires) —en adelante AFCM-. Carta de Fernando Fader a Federico C. Müller, 18 de septiembre de 1926. (Repr.: Antonio Lascano González, op. cit., p. 130). El párrafo hace referencia a José León Pagano, literato e influyente crítico de arte del diario La Nación de Buenos Aires, y a Marcelo T. de Alvear, Presidente de la República de Argentina entre 1922 y 1928.

${ }_{20}$ Atilio Chiappori, «Nuestro ambiente artístico y las modernas evoluciones técnicas (1907-1927)», Nosotros, Buenos Aires, núms. 219-220, 1927, pp. 233-234. 
saltó de la ingenua credulidad a la suspicaz desconfianza. Este fue el ánimo con que la guerra encontró a los coleccionistas argentinos, con la consecutiva ausencia de los «marchands» de antiguos. Era ya un poco tarde: la mayoría de nuestras galerías hallábanse comprometidas con un porcentaje más o menos elevado de telas falsas o dudosas ${ }^{21}$.

No obstante hacia 1915 se dio una sensible baja en el ritmo de adquisiciones debido a factores externos, como la guerra europea, que repercutió en la economía del país, limitándose las exportaciones e importaciones y alterando así el ritmo que éstas tenían en la Argentina, y factores internos como la preparación para las elecciones nacionales, mezcladas con la miseria y los despidos en masa de trabajadores. La exposición colectiva de la que participaron los artistas argentinos de mayor renombre, realizada por Müller en ese año, sólo llegó a vender, como dijimos, dos obras.

Los momentos de bajas en las ventas fueron superados gradualmente y para ello sirvió de móvil principal la acción de aquellos comerciantes que se vieron obligados a mostrar así su valía. Aun con la «desventaja» de ser alemán ${ }^{22}$, Federico C. Müller logró demostrar que daba la talla a la perfección, mostrándose a la par como el más preparado y supo salir adelante en sus negocios. Arrastró consigo a Fernando Fader al que equilibró definitivamente sus finanzas con la venta hecha a la recientemente creada Comisión de Bellas Artes de Rosario de la serie de ocho lienzos titulada «La vida de un día» a finales de 1917 en 7.200 pesos (fig. 5).

Müller tenía desde un par de años antes la exclusividad de ventas de obras de Fader. En 1920 Pedro Garmendia, amigo y antiguo mecenas del artista, se vio necesitado de vender algunos cuadros de éste que tenía en depósito, hecho que crispó los nervios de Müller, pero aquí quien mostró más visión de comerciante fue curiosamente el propio Fader, diciéndole a su marchand que se tranquilizase y fuera hábil para sacar tajada de la situación: «creo que Fader en su obra y en sus precios ha de subir aún y que la actual venta propuesta podría más adelante, proporcionarle mayor beneficio. Pero no haga nada para persuadirlo (a Garmendia) de que no debe vender. Al contrario. En sus manos será un experimento sumamente interesante. $Y$ si realiza la venta en otra parte, asegúrese un hombre de confianza para saber los precios obtenidos.

Si la venta se hace en su casa, sin perjuicio de ella, no estaría de más el anuncio de la exposición nueva - la que Fader presentaría durante ese año en el Salón Müller-, porque no se olvide que la gente, y es el mismo temor que tengo en toda esta historia, podría creer que es una maniobra mía para vender clavos viejos o a lo menos en combinación con nosotros. Esto me incomoda un poco. Porque también darán curso a la suposición de que ya no trabajo como antes o que mis cosas nuevas desmerecen las anteriores.

$Y a$ verá $U d$. todo lo que van a combinar e inventar. Lo principal es que Ud. tome bien el pulso a los amigos de su casa que compran mis cuadros si siguen acompañándome o no. Porque antes de exponernos a un retroceso en las ventas, que en nuestro ambiente significa una depreciación de la calidad artística, prefiero no exponer aquí...» ${ }^{23}$.

Años después, en 1924, cuando la relación entre Müller y Fader se hallaba deteriorada por diferencias de tipo económico, el primero le escribió al pintor: «Ud. ha sido en los últimos ocho años favorecido por la suerte en cuanto a la venta de sus cuadros con un resultado no igualado, ni aquí ni en Europa, por artista alguno de su edad —en ese momento Fader

21 Ibídem., p. 236.

22 En pleno desarrollo de la primera guerra mundial, Müller sufrió atentados a sus locales de exposición en Buenos Aires por parte de anónimos germanófobos.

23 AFCM. Carta de Fernando Fader a Federico C. Müller. Loza Corral, agosto de 1920. (Repr.: Antonio Lascano González, ob. cit., pp. 83-84. 
tenía 42 años- - y en este punto de su carrera artística, salvando al mismo tiempo su completa independencia y su prestigio de artista... Ha sido posible esto porque Ud. ha tenido también la suerte de encontrar un marchand, quien, sin ser exagerado en sus pretensiones, no ha ahorrado sus esfuerzos para valorizar su obra, pero este marchand ve con pesimismo su porvenir si Ud. no consigue hacer cortes radicales en sus gastos...» ${ }^{24}$.

Cuando en 1926 Müller regresó de Europa adonde se había marchado para intentar encauzar sus alicaídos negocios, escribió a Fader comentándole que llevaría a cabo una subasta de unos cuarenta cuadros en la casa Naón, y que planeaba organizar en la Asociación Amigos del Arte una exposición de estampas japonesas de los siglos XVIII y XIX y de cerámica del Extremo Oriente, y que lo que no vendiera allí también lo enviaría a subasta. Es interesante resaltar esto como una de las soluciones a las que recurrió el marchand para paliar su situación, ya sin su galería de la calle Florida, y solicitando a Amigos del Arte el alquiler de las salas y, en caso de que no vendiera las obras de la exposición, enviarlas a remate.

En 1932, año de la gran retrospectiva de Fader en el Palais de Glace, realizada con motivo de festejarse los cincuenta años del pintor, éste le escribió a Müller diciéndole que el cuadro «La Mazamorra», de 1926, «no debiera venderse por menos de 20.000 \$, no tanto por la importancia de la tela sino por ser una expresión mía definitivamente pasada» ${ }^{25}$. Aquí se ve una nueva pauta de cómo se definían los precios de ciertos cuadros; el hecho de que una obra perteneciera a un período definitivamente acabado en la trayectoria de un artista podía incidir en el aumento de su precio.

Las producciones y ventas de obras de arte supieron estar conectadas con el éxito de determinadas escuelas y temáticas. Por casos en la Argentina tenemos el del propio Fader al pintar en 1914 «Los mantones de Manila» emulando en gran medida a los pintores españoles que de tanta aceptación gozaban en el país, o ya en los años veinte cuando reconoció haber hecho todo lo contrario de lo que quería y resultando de ello «cuadros de venta».

En el año 1924, Juan José de Soiza Reilly afirmó sobre Carlos De la Torre que era «el único pintor argentino que vende todos los cuadros que expone». Agregó no sin cierta sorna: «Y jcon qué habilidad estética el público rico los adquiere! Esa habilidad me permite calcular el grado de cultura artística de los compradores distinguidos. En la última exposición exhibió cuarenta y nueve cuadros. Vendió cuarenta y ocho. (Precisamente, el único que no vendió, el número 28 , era el mejor hechito!...)

El señor De la Torre - me decía uno de los porteros de Witcomb-es el más célebre de todos los pintores. Sus cuadros se venden sin necesidad de esperar el juicio de los diarios. Los compradores, sin ver las telas, piden con antelación, y por teléfono, que se las reserven, como las localidades de los teatros» ${ }^{26}$.

Contamos, pues, con la afirmación de que De la Torre es «el único pintor argentino» que vendía todos sus cuadros en una exposición. Habría aquí que hilar más fino ya que eran varios los artistas que lograban colocar sus pinturas en el mercado en un alto porcentaje. Se nota, además, cuan lejos habían quedado los tiempos de escasez de ventas.

En el citado testimonio del portero de la sala Witcomb se habla de De la Torre como de «el más célebre» de los pintores argentinos, basando la afirmación en que vende todas sus

24 AFCM. Carta de Federico C. Müller a Fernando Fader, Buenos Aires, 30 de mayo de 1924. (Repr.: Antonio Lascano González, ob. cit., pp. 115-116).

${ }_{25}$ AFCM. Carta de Fernando Fader a Federico C. Müller. Loza Corral, 9 de agosto de 1932. (Repr.: Antonio Lascano González, ob. cit., p. 160).

26 Juan José de Soiza Reilly, «Carlos De la Torre frente a Emilio Pettoruti», El Hogar, Buenos Aires, 24 de octubre de 1924, p. 8. 

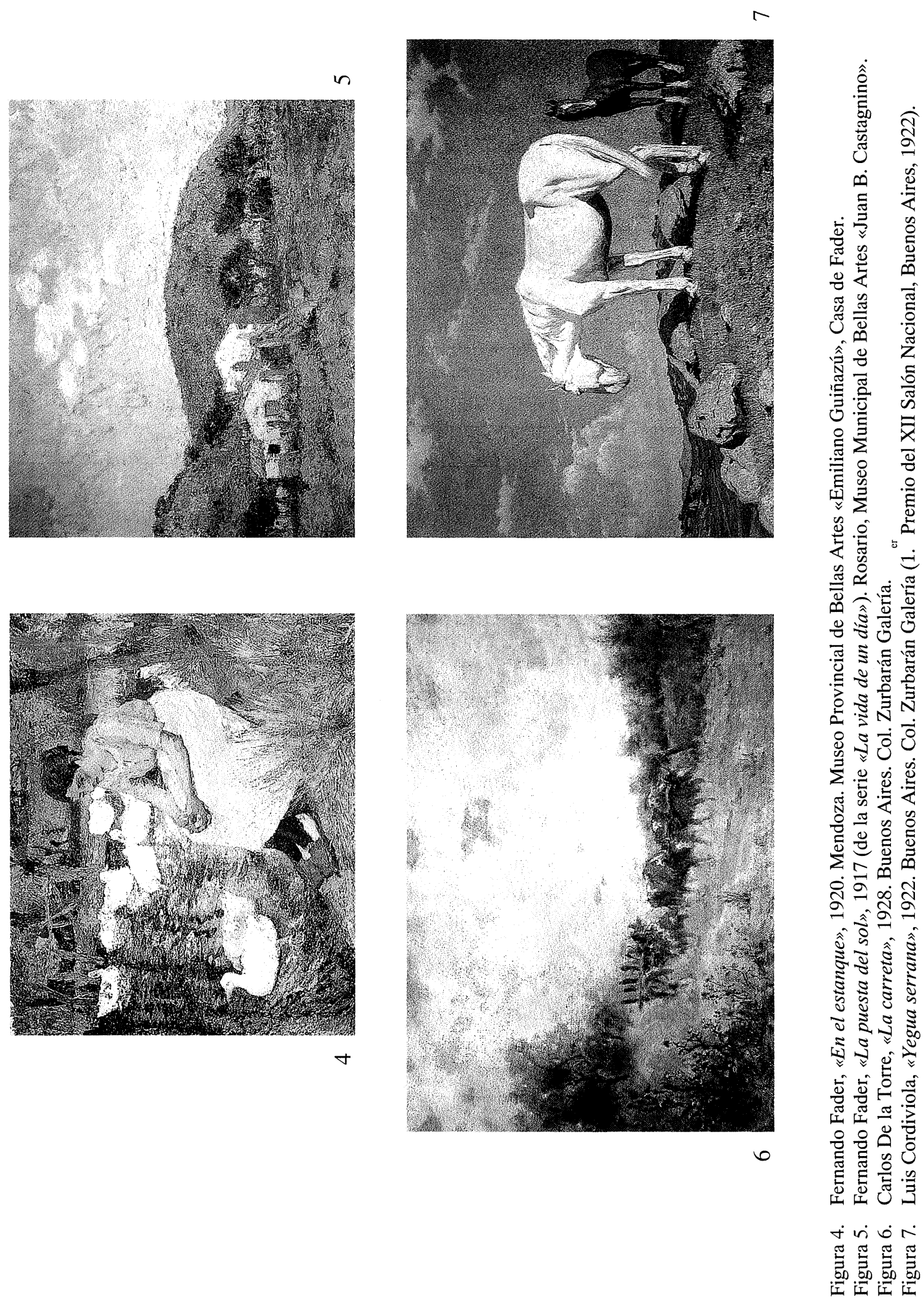
obras. La calidad, por lo que se aprecia, quedaba así supeditada al éxito de ventas en lo que respecta a la valoración de los artistas. Sin negarle valor a De la Torre, había en aquel momento muchos pintores de mayor envergadura, por citar sólo dos ejemplos Atilio Malinverno o Luis Cordiviola, cuyas obras engrosaron numerosas colecciones particulares durante los años veinte y bien entrados los treinta (fig. 7).

Se deja entrever, asimismo, que las preocupaciones pictóricas para cierto público no pasaban por cuestiones de estética sino de temática. Adquirían obras por teléfono, sin verlas con anterioridad, a sabiendas de que se trataba de imágenes del campo argentino.

En España, en el último cuarto del XIX, se habían producido situaciones similares con respecto a la pintura de Mariano Fortuny, a quien siguieron estéticamente artistas como José Casado del Alisal, Antonio Gisbert y Vicente Palmaroli. Al decir de Lafuente Ferrari, «Casado estaba "cansado de no vender" $\mathrm{y}$ "no ha de extrañarnos que el gran pintor palentino, medallado por sus cuadros de historia y excelente retratista, cayera también en la tentación de hacer un fortunysmo que tan rentable era económicamente...» ${ }^{27}$.

En 1910 Rafael Doménech reflexionaba: «Romero de Torres tratando de imitar la técnica de los maestros del siglo XV al XVI, Santamaría plagiando a los venecianos, y Corredoira al Greco, ¿no comprenden que por un miserable plato de lentejas viejas venden su personalidad, que es como si renegaran de sus nombres y de su tiempo?... ¿no han pensado esos pintores que sus cuadros vienen al mundo muy viejos para que su conservación sea posible durante muchos años?...

¿Qué será, dentro de pocos años, de esos cuadros de la actual Exposición, que salen de las manos de sus autores más viejos que los cuadros de un Museo?... Está bien que para el negocio de chamarilero se hagan habilidades, no sólo por imitar a un maestro o a una época, sino también para convertir un cuadro moderno en viejo, con cuarteados y desconchados, patinas, suciedades, veladuras, manchas de barniz enranciado, etc., etc.; pero cuando se trata de hacer una obra de arte original, en que el artista ha de poner todo lo que es él y todo lo que sabe, esas habilidades y trampas están fuera de lugar» ${ }^{28}$.

Sirvan estas líneas de Doménech para seguir advirtiéndonos a los historiadores de arte argentino de una realidad cuyos alcances aún no han sido estudiados a fondo, en cuanto a la incidencia del mercado de arte en la producción artística de nuestro país, en este caso en las primeras décadas de siglo. Que también las propias necesidades económicas de los artistas -no solamente para la supervivencia personal, sino también para alquilar taller, adquirir bastidores, tubos de pintura y otros enseres que solían alcanzar altos preciosdeterminaron su inclinación por temáticas de consumo (por lo general paisajes, costumbres y retratos) que les permitieran seguir produciendo. No obstante, lejos estamos de considerar «tramposos» a estos artistas, como lo hizo Doménech con sus compatriotas: la mayoría de ellos desarrollaron su labor con afán y convencimiento en su arte, y para el caso, imbuidos en las ideologías nacionalistas y americanistas que vivieron en esos años una Edad de Oro en la Argentina.

27 Enrique Lafuente Ferrari, Breve historia de la pintura española, Madrid, 1953, p. 204.

28 Rafael Doménech y otros, Exposición Nacional de Bellas Artes. Año MCMX, Madrid, 1910, p. 32. 